\title{
Reactions of Auranofin and its Pseudohalide Derivatives with Serum Albumin Investigated through ESI-Q-TOF MS
}

\author{
Alessandro Pratesi,${ }^{*, \dagger}$ Damiano Cirri, ${ }^{\dagger}$ Lorenzo Ciofi, ${ }^{\dagger}$ and Luigi Messori ${ }^{*, \dagger}$ \\ ${ }^{\dagger}$ Laboratory of Metals in Medicine (MetMed), Department of Chemistry “U. Schiff”, University of Florence, Via \\ della Lastruccia 3, Postal Code 50019 Sesto Fiorentino, Italy. \\ Corresponding authors email: alessandro.pratesi@unifi.it ; luigi.messori@unifi.it
}

Supporting Information Placeholder

\begin{abstract}
The reactions of auranofin and three pseudohalide derivatives with bovine serum albumin were explored by ESI-Q-TOF mass spectrometry; a detailed molecular description of the resulting adducts is achieved revealing even subtle differences in reactivity within this series of gold(I) complexes. Our study shows that this kind of investigative approach, formerly applied to the interactions of metal-based drugs with small model proteins of MW 10-15 kDa, e.g. cytochrome c and lysozyme, may now be extended with success to far larger proteins such as serum albumin (MW 66 kDa).
\end{abstract}

Auranofin (AF hereafter) is an established gold(I) drug for the treatment of severe rheumatoid arthritis first approved for clinical use in 1985 . In recent years, owing to the implementation of so called "drug repurposing strategies", a great therapeutic potential was disclosed for $\mathrm{AF} ;{ }^{1-3} \mathrm{AF}$ is now being evaluated as an experimental drug for several parasitic and microbial diseases, and also for various types of cancers, with encouraging results. ${ }^{4-6}$

Conversely, serum albumin (MW $66429 \mathrm{Da}$ ) is one of the most widely studied mammalian proteins being the most abundant protein in the plasma with a concentration of about $0.3 \mathrm{mM}$. The aminoacidic chain of serum albumin contains 583 residues; it is characterised by the presence of 17 disulphide bonds and one free cysteine residue (Cys34). ${ }^{7}$ Serum albumin is the major carrier for AF in the blood; the interactions of AF with this protein already attracted much attention in the past. In particular, this topic was studied in depth by Frank Shaw and co-workers in the late 8os/early 9os: owing to the application of various independent biophysical methods these authors could demonstrate that AF binds tightly and specifically (bovine) serum albumin through gold(I) coordination to the free thiol group of Cys34 following the release of the 1-thiobeta-D-glucose-2,3,4,6-tetraacetate ligand. ${ }^{8}$

Taking advantage of the considerable technological progresses recorded in the last decade in the field of mass spectrometry, we have now revisited the reaction of AF with serum albumin using a Sciex TripleTOF $5600+$ MS instrument, that represents the cutting-edge technology in high resolution mass spectrometry. In addition, we have explored
Chart 1. The four investigational $\mathrm{Au}(\mathrm{I})$ compounds: $\operatorname{AFCN}(1), \operatorname{AFSCN}(2), \operatorname{AFN}_{3}(3)$ and AF (4).
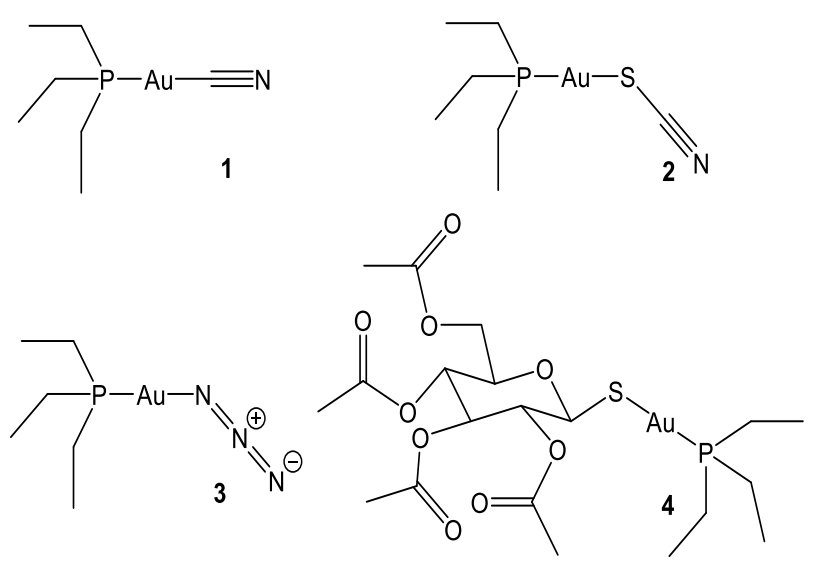

comparatively the reactions of serum albumin with three AF analogues bearing triethylphosphine and a pseudohalide as ligands. ${ }^{9}$

Quite surprisingly, until a few years ago, the scientific literature was virtually devoid of any relevant mass spectrometric study describing metallodrug-protein interactions apart from a few relevant exceptions. ${ }^{10,11}$ However, during the past few years, our research group has gained a considerable expertise in the investigation of metallodrugs' reactions with proteins relying on extensive and systematic ESI-MS studies of the adducts that metallodrugs form with various small proteins such as lysozyme, cytochrome c and ribonuclease A. ${ }^{12-14}$ Thanks to some recent research efforts, ${ }^{15-17}$ ESI mass spectrometry has emerged as an important tool to characterise the metallodrugs' interactions with biomolecules and potential targets at the molecular level and also to predict their probable reactivity and mode of action within complex biological samples. ${ }^{18}$ In spite of that, the study of the interactions of metallodrugs with larger proteins in their intact form still posed too severe challenges to be faced with the instrumentation then available and remained largely unaddressed. It is just worth reminding that an original MS study concerning the reactions of a few gold drugs with albumin, was 


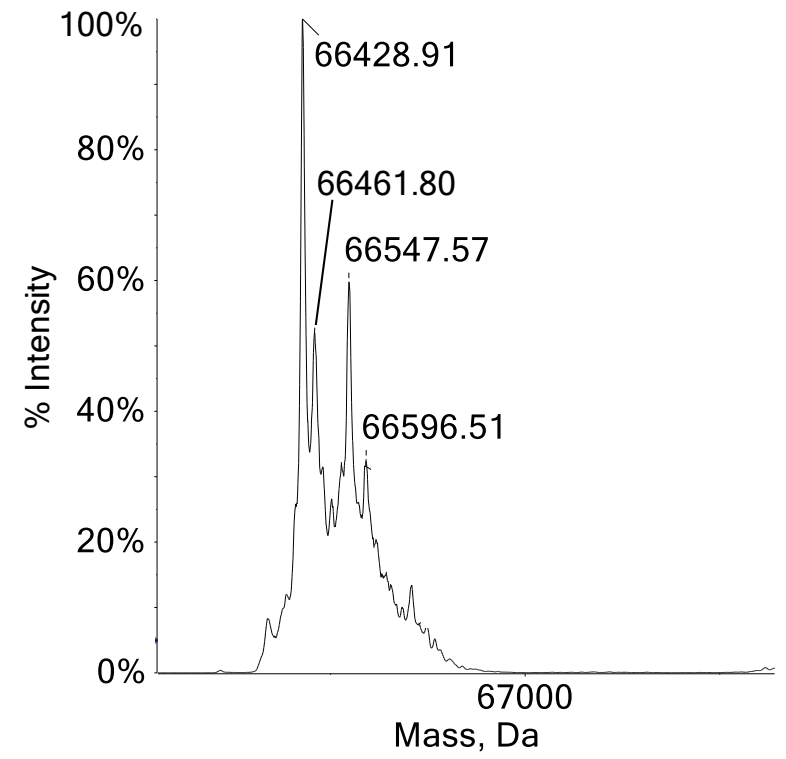

Figure 1. Deconvoluted ESI-MS spectrum of BSA solution $10^{-5}$ $\mathrm{M}$ in $20 \mathrm{mM}$ ammonium acetate buffer, $\mathrm{pH} 6.8$.

reported in 2006 by Ralph and co-workers: a rather satisfactory description of the metallodrug-protein adducts was obtained but details were missed due to the lower analytical performances of the instrumentation available at the time. ${ }^{19}$ Taking advantage of the newly available MS instrumentation, we are now in the conditions to analyse in detail the interactions of metallodrugs with proteins as large as albumins, obtaining in a very short time good-quality and highly informative highresolution MS spectra on very diluted samples $\left(10^{-6} \mathrm{M}\right)$. The panel of gold compounds that we have used for this study is shown in chart 1; the panel includes, beyond AF (4), three of its analogues where a pseudohalide, namely cyanide (AFCN, 1), thiocyanate $(\mathrm{AFSCN}, \mathbf{2})$ or azide $\left(\mathrm{AFN}_{3}, 3\right)$, replaces the 1thio-beta-D-glucose-2,3,4,6-tetraacetate ligand. These gold(I) compounds were prepared by simple synthetic procedures as previously reported. ${ }^{9}$ Notably, these compounds are sufficiently soluble and stable in aqueous solutions for the time needed to perform the described experiments. ${ }^{20}$ The interactions occurring between the four gold compounds and bovine serum albumin (BSA) were investigated according to the wellestablished ESI-MS protocol previously developed in our laboratory to study the reactions between metal based drugs and small model proteins. ${ }^{21-23}$ First of all, the ESI-MS spectrum of a control sample of native and commercially available BSA was recorded (Figure 1). The main peak at $\mathrm{m} / \mathrm{z} 66428.91 \mathrm{Da}$ corresponds to the native free protein while the other major peak at 66547.57 Da, with a mass shift of $+118.66 \mathrm{Da}$, is perfectly consistent with an additional cysteine (+119 Da) bound to Cys34. Indeed, both human and bovine serum albumin normally show characteristic post-translational modifications (PTMs), such as cysteinylation, involving the unique cysteine residue normally present as a free thiol. ${ }^{19,24}$ The signal at 66461.80 Da is tentatively assigned to a protein species bearing oxidized $\mathrm{Cys} 34\left(\mathrm{Cys}-\mathrm{SO}_{2} \mathrm{H}\right)$ in agreement with previous suggestions. In fact, about one-fourth of circulating albumin is known to be present as mixed disulphides with cysteine, while in the remaining fraction the thiol may be oxidized to higher oxidation states including sulfinic acid $\left(\mathrm{RSO}_{2} \mathrm{H}\right) .{ }^{25,26}$ These observations are well consistent with the presence of significant amounts of reactive oxygen species (ROS) in cells and tissues; indeed, it is well-known that the free thiol group of BSA plays a key role in several ROS scavenging mechanisms undergoing progressive oxidation. ${ }^{25}$ Lastly, the signal at 66596.51 Da belongs to a glycated form of BSA, also in this case present in native serum proteins. ${ }^{27}$

Afterwards, the three investigational $\mathrm{Au}(\mathrm{I})$ compounds, i.e. AFCN (1), AFSCN (2) and $\operatorname{AFN}_{3}$ (3), were individually challenged with BSA in aqueous solutions at physiological $\mathrm{pH}$, at a metal to protein ratio of 3:1; aliquots of each sample were then taken at increasing time intervals after mixing (namely at 1, 24, 48, $72 \mathrm{~h}$ ) and the respective ESI-MS spectra recorded in the positive ion mode. In all cases, extensive metalation of the protein was soon apparent already after $1 \mathrm{~h}$ incubation, suggesting the establishment of rapid and specific interactions. The spectrum depicted in Figure $2 \mathrm{~A}$, acquired after only $1 \mathrm{~h}$ of incubation, shows that in the case of AFCN (1) the main adduct (66742.20 Da) well corresponds to a single $\mathrm{AuPEt}_{3}{ }^{+}$ moiety bound to the protein. This is perfectly consistent with the presence of one specific gold binding site on BSA having a much greater affinity than any other binding site. A similar behaviour was also found for AFSCN (2) (Figure $2 \mathrm{~B}$ ) with the formation of the same type of mono-adduct; yet, in the latter case, we noticed a larger reactivity that is indicated by the peculiar formation of a bis-adduct with BSA, corresponding to the BSA $+2 \mathrm{AuPEt}_{3}{ }^{+}$species $(67056.24 \mathrm{Da})$. Despite the presence of only one reactive cysteine in BSA, the formation of a bis-gold adduct is not in contrast with previous reports: as a matter of fact, a similar reactivity was already proposed and documented in the literature for similar $\mathrm{Au}(\mathrm{I})$ compounds that were reported to form a thiolate-bridged bis-gold complex on Cys34 in BSA. ${ }^{8}$

The greater reactivity of AFSCN (2) compared to AFCN (1) may well be explained by the stronger nucleophilic character of $\mathrm{CN}^{-}$compared to $\mathrm{SCN}^{-}$, making the first compound far more reactive toward the thiol group. ${ }^{28}$ To this regard, the reactivity of $\mathrm{AFN}_{3}$ (3) is similarly emblematic; due to the greater propensity of the azido group to leave gold(I) coordination and produce the $\mathrm{AuPEt}_{3}{ }^{+}$moiety, the bis-adduct with BSA (67056.34 $\mathrm{Da})$ was the only species formed in the same kind of reaction (Figure $2 \mathrm{C}$ ).

Since AFCN (1), AFSCN (2) and $\operatorname{AFN}_{3}(3)$ are structurallyrelated to auranofin $(A F, 4)$, this led us to repeat the same type of experiment with AF. Compound 4 was incubated with BSA under identical solution conditions and the mass spectrum depicted in Figure $2 \mathrm{D}$ obtained after $1 \mathrm{~h}$. A single main adduct at $66742.95 \mathrm{Da}$ is observed corresponding, once again, to the binding of the AuPEt${ }_{3}{ }^{+}$moiety to the free thiol group of Cys34. This finding is again in nice agreement with literature data where the thiosugar ligand, present in AF (4), is described as the "leaving group" in this molecule and the $\mathrm{AuPEt}_{3}{ }^{+}$portion is reputed as the biologically-active molecular fragment. ${ }^{29-31}$ The three other signals present in the spectrum at 66429.40, 66460.38 and $66546.61 \mathrm{Da}$ are assigned to unreacted BSA and its PTMs, as previously described. When the incubation time was extended to 24,48 and $72 \mathrm{~h}$, some appreciable changes in the adducts distribution progressively occurred (See ESI-MS spectra in SI). In particular, for AFSCN (2) the equilibrium between mono- and bis-adduct moved backward with time toward a net preponderance of the monoadduct. However, at this stage of the research, we are 

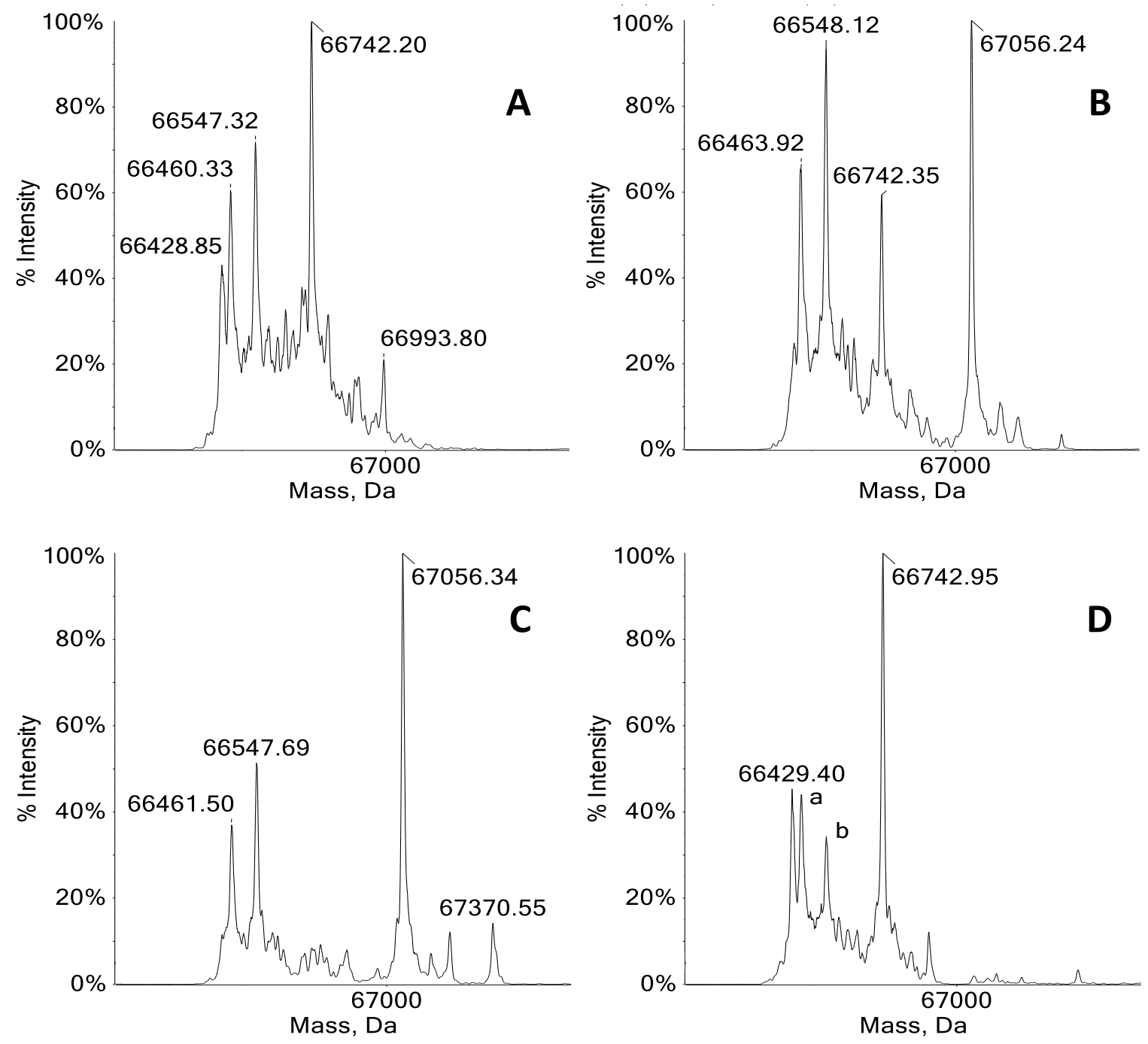

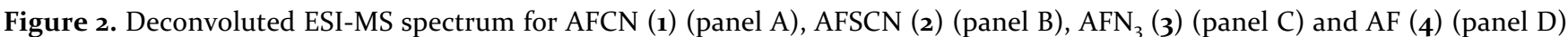
incubated for $1 \mathrm{~h}$ with bovine serum albumin $10^{-4} \mathrm{M}\left(3: 1\right.$ metal to protein molar ratio) at $37^{\circ} \mathrm{C}$ in $20 \mathrm{mM}$ ammonium acetate buffer, $\mathrm{pH}$ 6.8. Peak (a) is $66460.38 \mathrm{Da}$, peak (b) is $66546.61 \mathrm{Da}$.

not able to understand in full the reasons for this behavior; probably the observed shift in the mono/bis-adduct equilibrium is due to the greater thermodynamic stability of the mono-adduct and to its diminished steric hindrance. On the other hand, for AFCN (1) the major protein complex still was the mono-adduct, while for $\mathrm{AFN}_{3}$ (3) the presence and the relative abundance of the bis-adduct remained unchanged with time. As expected, in the case of AF (4), BSA + $\mathrm{AuPEt}_{3}{ }^{+}$was the only species observed in the ESI-MS spectra recorded over 72 $\mathrm{h}$ (Figure $2 \mathrm{D}$ ). As mentioned above, a couple of PTMs of native BSA are detected in all mass spectra recorded after $1 \mathrm{~h}$ of incubation with unchanged relative abundances. It is interesting to note as for incubation times greater than $24 \mathrm{~h}$ the signals belonging to these PTMs progressively disappear. Probably, the higher stability of the Au-S bond compared to S-S, and the presence of an excess of the free gold compounds in solution determined the progressive decrease of these PTMs with a consequent increase in gold-BSA adduct formation.

It is remarkable that in all cases the phosphane ligand remains coordinated to the gold(I) center while the pseudohalide ligand is replaced by the thiol group, in agreement with previous observations by Shaw ${ }^{8}$ and Bierbach. ${ }^{32}$ Also, a rather clear correlation between the chemical features of the three pseudohalide leaving groups (the order of nucleophilicity being $\mathrm{CN}^{-}>\mathrm{SCN}^{-}>\mathrm{N}_{3}{ }^{-}$) and their reactivity with the thiol group could be established. In fact, depending on the nature of the pseudohalide, the reactivity of the various gold complexes towards this biological target varied accordingly. ${ }^{33}$ In other words, a sort of fine-tuning of the reactivity, and then of the typology of metal/protein adducts formed, was easily and uniquely revealed through ESI-MS.

In conclusion we have shown here that high resolution ESIQ-TOF MS experiments, owing to the latest technological advancements, offer today a straightforward and excellent tool to analyse the reactions of metal-based drugs with proteins as large as serum albumin. Remarkably, these experiments are carried out through direct sample infusion with minimal sample manipulation and minimal sample consumption. Detailed information is gained on protein speciation and adduct formation. In addition, as ESI-MS spectra are obtained in a very short time, detailed time course experiments may be carried out easily. The method is so informative that in spite of the occurrence of roughly the same kind of reactivity between the various gold(I) complexes and BSA, subtle differences in the 
kinetics of adduct formation and in the nature and distribution of the formed adducts could be highlighted. This kind of approach will now be extended to characterize the adducts that this important serum protein does form with other metalbased drugs of even greater biological and medical relevance.

\section{ASSOCIATED CONTENT}

\section{Supporting Information}

Listing of experimental details and ESI-MS spectra. This material is available free of charge via the Internet at http://pubs.acs.org.

\section{AUTHOR INFORMATION}

\section{Corresponding Authors}

*E-mail: alessandro.pratesi@unifi.it

*E-mail: luigi.messori@unifi.it

\section{Notes}

The authors declare no competing financial interests.

\section{ACKNOWLEDGMENT}

We gratefully acknowledge AIRC for funding the projects (IG16049) and "Advanced mass spectrometry tools for cancer research: novel applications in proteomics, metabolomics and nanomedicine" (Multi-user Equipment Program 2016, Ref. code 19650). Also, we acknowledge Beneficentia Stiftung, ITT (Istituto Toscano Tumori) and Ente Cassa Risparmio Firenze (ECR).

\section{REFERENCES}

(1) Celegato, M.; Borghese, C.; Casagrande, N.; Mongiat, M.; Kahle, X. U.; Paulitti, A.; Spina, M.; Colombatti, A.; Aldinucci, D. Preclinical Activity of the Repurposed Drug Auranofin in Classical Hodgkin Lymphoma. Blood 2015, 126, 1394-1397.

(2) Varbanov, H. P.; Kuttler, F.; Banfi, D.; Turcatti, G.; Dyson, P. J. Repositioning Approved Drugs for the Treatment of Problematic Cancers Using a Screening Approach. PLoS ONE 2017, 12, eo171052.

(3) Landini, I.; Lapucci, A.; Pratesi, A.; Massai, L.; Napoli, C.; Perrone, G.; Pinzani, P.; Messori, L.; Mini, E.; Nobili, S. Selection and Characterization of a Human Ovarian Cancer Cell Line Resistant to Auranofin. Oncotarget 2017, 8, 96062-96078.

(4) May, H. C.; Yu, J.-J.; Guentzel, M. N.; Chambers, J. P.; Cap, A. P.; Arulanandam, B. P. Repurposing Auranofin, Ebselen, and PX-12 as Antimicrobial Agents Targeting the Thioredoxin System. Front. Microbiol. 2018, 9, 336.

(5) Thangamani, S.; Maland, M.; Mohammad, H.; Pascuzzi, P. E.; Avramova, L.; Koehler, C. M.; Hazbun, T. R.; Seleem, M. N. Repurposing Approach Identifies Auranofin with Broad Spectrum Antifungal Activity That Targets Mia4o-Ervı Pathway. Front. Cell. Infect. Microbiol. 2017, 7, 4. Doi: 10.3389/fcimb.2017.00004.

(6) Hou, G.-X.; Liu, P.-P.; Zhang, S.; Yang, M.; Liao, J.; Yang, J.; Hu, Y.; Jiang, W.-Q.; Wen, S.; Huang, P. Elimination of Stem-Like Cancer Cell Side-Population by Auranofin through Modulation of ROS and Glycolysis. Cell Death E Disease 2018, 9, 89. Doi: 10.1038/s41419-017o159-4.

(7) Rombouts, I.; Lagrain, B.; Scherf, K. A.; Lambrecht, M. A.; Koehler, P.; Delcour, J. A. Formation and Reshuffling of Disulfide Bonds in Bovine Serum Albumin Demonstrated Using Tandem Mass Spectrometry with Collision-Induced and Electron-Transfer Dissociation. Scientific Reports 2015, 5, 12210.

(8) Isab, A. A.; Shaw III, C. F.; Hoeschele, J. D.; Locke, J. Reactions of Trimethylphosphine Analogues of Auranofin with Bovine Serum Albumin. Inorg. Chem. 1988, 27, 3588-3592.
(9) El-Etri, M. M.; Scovell, W. M. Synthesis and Spectroscopic Characterization of (Triethylphosphine)gold(I) Complexes $\mathrm{AuX}\left(\mathrm{PEt}_{3}\right)(\mathrm{X}=$ $\mathrm{Cl}, \mathrm{Br}, \mathrm{CN}, \mathrm{SCN}),\left[\mathrm{AuL}\left(\mathrm{PEt}_{3}\right)^{+}\right]\left(\mathrm{L}=\mathrm{SMe}_{2}, \mathrm{SC}\left(\mathrm{NH}_{2}\right)_{2}, \mathrm{H}_{2} \mathrm{O}\right)$, and (.mu.$\mathrm{S})\left[\mathrm{Au}\left(\mathrm{PEt}_{3}\right)\right]_{2}$. Inorg. Chem. 1990, 29, 480-484.

(10) Gabbiani, C.; Casini, A.; Mastrobuoni, G.; Kirshenbaum, N.; Moshel, O.; Pieraccini, G.; Moneti, G.; Messori, L.; Gibson, D. Peculiar Mechanistic and Structural Features of the Carboplatin-Cytochrome c System Revealed by ESI-MS Analysis. J. Biol. Inorg. Chem. 2008, 13, 755-764.

(11) Balter, L.; Gibson, D. Mass Spectrometric Studies of the Formation and Reactivity of trans- $\left[\mathrm{PtCl}_{2}(\mathrm{Am})\right.$ (piperidinopiperidine) $\cdot \mathrm{HCl}$ Complexes with Ubiquitin. Rapid Commun. Mass Spectrom. 2005, 19, 3666-3672.

(12) Marzo, T.; De Pascali, S. A.; Gabbiani, C.; Fanizzi, F. P.; Messori, L.; Pratesi, A. ESI-MS Studies of the Reactions of Novel Platinum(II) Complexes Containing $O, O^{\prime}$-Chelated Acetylacetonate and Sulfur Ligands with Selected Model Proteins. Biometals 2017, 30, 609-614.

(13) Casini, A.; Gabbiani, C.; Michelucci, E.; Pieraccini, G.; Moneti, G.; Dyson, P. J.; Messori, L. Exploring Metallodrug-Protein Interactions by Mass Spectrometry: Comparisons between Platinum Coordination Complexes and an Organometallic Ruthenium Compound. J. Biol. Inorg. Chem. 2009, 14, 761-770.

(14) Messori, L.; Merlino, A. Protein Metalation by Metal-Based Drugs: X-Ray Crystallography and Mass Spectrometry Studies. Chem. Commun. 2017, 53, 11622-11633.

(15) Esteban-Fernández, D.; Moreno-Gordaliza, E.; Cañas, B.; Palacios, M. A.; Gómez-Gómez, M. M. Analytical Methodologies for Metallomics Studies of Antitumor Pt-Containing Drugs. Metallomics 2010, $2,19-38$.

(16) Meier, S. M., Babak, M. V.; Keppler, B. K.; Hartinger, C. G. Efficiently Detecting Metallodrug-Protein Adducts: Ion Trap versus Time-of-Flight Mass Analyzers. ChemMedChem. 2o14, 9, 1351 - 1357.

(17) Moreno-Gordaliza, E.; Cañas, B.; Palacios, M. A.; GómezGómez, M. M. Top-Down Mass Spectrometric Approach for the Full Characterization of Insulin-Cisplatin Adducts. Anal. Chem. 2009, 81, 3507-3516.

(18) Hartinger, C. G.; Groessl, M.; Meier, S. M.; Casini, A.; Dyson, P. J. Application of Mass Spectrometric Techniques to Delineate the Modes-of-Action of Anticancer Metallodrugs. Chem. Soc. Rev. 2013, 42, 6186-6199.

(19) Talib, J.; Beck, J. L., Ralph, S. F. A Mass Spectrometric Investigation of the Binding of Gold Antiarthritic Agents and the Metabolite $\left[\mathrm{Au}(\mathrm{CN})_{2}\right]^{-}$to Human Serum Albumin. J. Biol. Inorg. Chem. 2oo6, 11, 559-570.

(20) Hormann-Arendt, A. L.; Shaw III, C. F. Ligand-Scrambling Reactions of Cyano(Trialkyl/Triarylphosphine)Gold(I) Complexes: Examination of Factors Influencing the Equilibrium Constant. Inorg. Chem. 1990, 29, 4683-4687.

(21) Michelucci, E.; Pieraccini, G.; Moneti, G.; Gabbiani, C.; Pratesi, A.; Messori, L. Mass Spectrometry and Metallomics: a General Protocol to Assess Stability of Metallodrug-Protein Adducts in Bottom-Up MS Experiments. Talanta 2017, 167, 30-38.

(22) Pratesi, A.; Cirri, D.; Đurović, M. D.; Pillozzi, S.; Petroni, G.; Bugarčić, Ž. D.; Messori, L. New Gold Carbene Complexes as Candidate Anticancer Agents. Biometals 2016, 29, 905-911.

(23) Biancalana, L.; Pratesi, A.; Chiellini, F.; Zacchini, S.; Funaioli, T.; Gabbiani, C.; Marchetti, F. Ruthenium Arene Complexes with Triphenylphosphane Ligands: Cytotoxicity Towards Pancreatic Cancer cells, Interaction with Model Proteins, and Effect of Ethacrynic Acid Substitution. New J. Chem. 2017, 41, 14574-14588.

(24) Hargreaves, I. P.; Lee, P. J.; Briddon, A. Homocysteine and Cysteine - Albumin Binding in Homocystinuria: Assessment of Cysteine Status and Implications for Glutathione Synthesis? Amino Acids 2002, 22, 109-118.

(25) Carballal, S.; Alvarez, B.; Turell, L.; Botti, H.; Freeman, B. A.; Radi, R. Sulfenic Acid in Human Serum Albumin. Amino Acids 2007, 32, 543-551.

(26) Devarie Baez, N. O.; Reisz, J. A.; Furdui, C. M. Mass Spectrometry in Studies of Protein Thiol Chemistry and Signaling: Opportunities and Caveats. Free Radic. Biol. Med., 2015, 8o, 191-211. 
(27) Baldassarre, M.; Naldia, M.; Domenicali, M.; Volo, S.; Pietra, M.; Dondi, F.; Caraceni, P.; Peli, A. Simple and rapid LC-MS method for the determination of circulating albumin microheterogeneity in veal calves exposed to heat stress. J. Pharm. Biomed. Anal., 2017, 144, 263-268.

(28) Alzoubi, B. M.; Hamza, M. S. A.; Dücker-Benfer, C.; van Eldik R. Equilibrium, Kinetic and Leaving Group Effect Studies on Ligand Substitution Reactions of a Simple Model for Coenzyme $B_{12}$. Eur. J. Inorg. Chem. 2002, 4, 968-974.

(29) Darabi, F.; Marzo, T.; Massai, L.; Scaletti, F.; Michelucci, E.; Messori, L. Reactions of Model Proteins with Aurothiomalate, a Clinically Established Gold(I) Drug: The Comparison with Auranofin. J. Inorg. Biochem. 2015, 149, 102-107.

(30) Marzo, T.; Cirri, D.; Gabbiani, C.; Gamberi, T.; Magherini, F.; Pratesi, A.; Guerri, A.; Biver, T.; Binacchi, F.; Stefanini, M.; Arcangeli, A., Messori, L. Auranofin, $\mathrm{Et}_{3} \mathrm{PAuCl}$, and $\mathrm{Et}_{3} \mathrm{PAuI}$ Are Highly Cytotoxic on Colorectal Cancer Cells: A Chemical and Biological Study. ACS Med. Chem. Lett. 2017, 8, 997-1001.

(31) Gabbiani, C.; Massai, L.; Scaletti, F.; Michelucci, E.; Maiore, L.; Cinellu, M. A.; Messori, L. Protein Metalation by Metal-Based Drugs: Reactions of Cytotoxic Gold Compounds with Cytochrome c and Lysozyme. J. Biol. Inorg. Chem. 2012, 17, 1293-1302.

(32) Dean, T. C.; Yang, M.; Liu, M.; Grayson, J. M.; DeMartino, A. W.; Day, C. S.; Lee, J.; Furdui, C. M.; Bierbach, U. Human Serum Albumin-Delivered $\left[\mathrm{Au}\left(\mathrm{PEt}_{3}\right)\right]^{+}$Is a Potent Inhibitor of T Cell Proliferation. ACS Med. Chem. Lett. 2017, 8, 572-576.

(33) Shaw III, C. F. in Metal Compounds in Cancer Therapy, ed. S.P. Fricker, Springer Science+Businnes Media, Dordrecht, $1^{\text {st }}$ edn, 1994, ch. 3, 46-61. 


\section{Table of Contents Graphic and Synopsis}

\section{Reactions of Auranofin and its Pseudohalide Derivatives with Serum Albumin Investigated through ESI-Q-TOF MS}

\section{Alessandro Pratesi, Damiano Cirri, Lorenzo Ciofi, and Luigi Messori}

A detailed molecular description of adducts formed by auranofin and three pseudohalide derivatives with bovine serum albumin was achieved by high resolution ESI-Q-TOF mass spectrometry, revealing even subtle differences in gold compounds' reactivity.
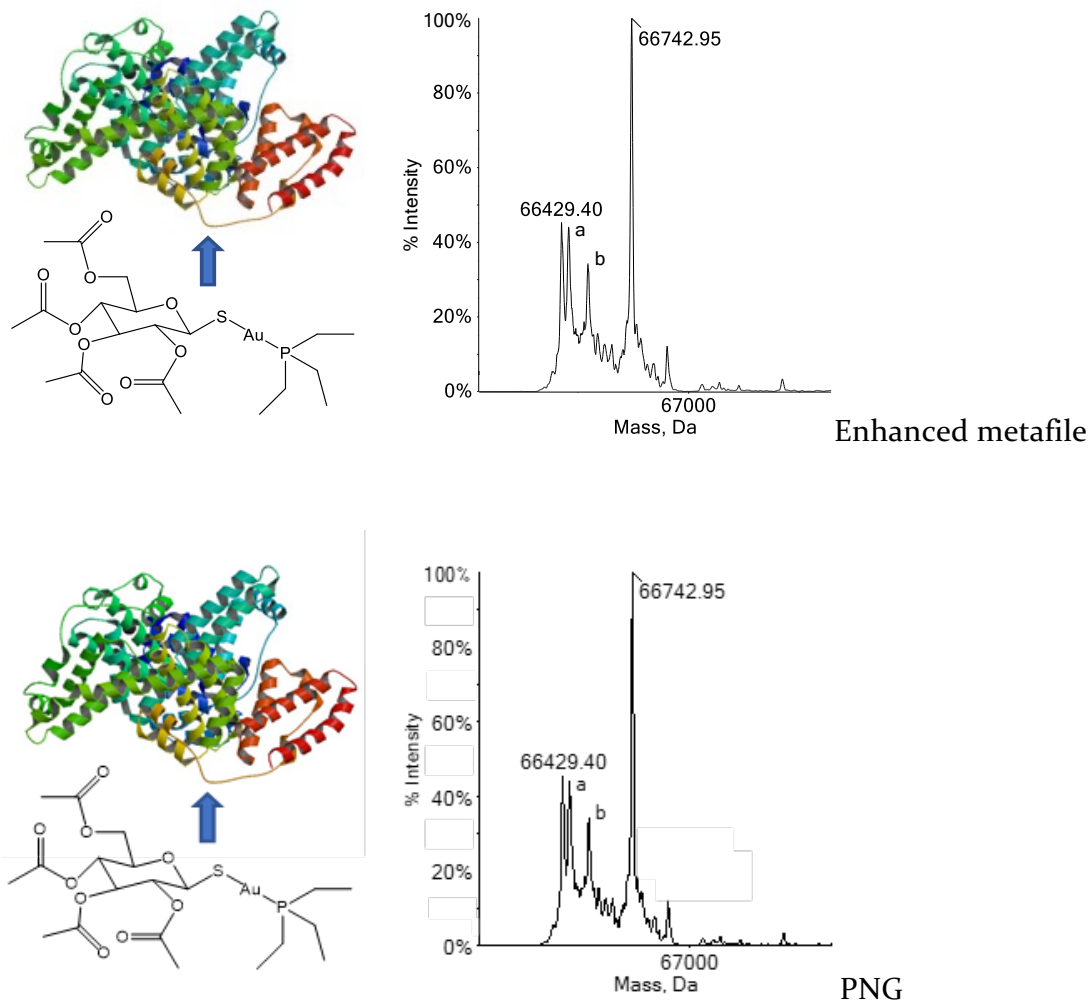